\title{
Improving management accounting education through the use of interventionist action research
}

\author{
Bernt Arne Bertheussen
}

This is the last author version. The paper is published in Beta - The Scandinavian Journal of Business Research, 2(31), 170-183, doi: 10.18261/ISSN.1504-3134-2017-02-05

\begin{abstract}
The purpose of the present study was to improve management accounting education through teacher initiated curriculum innovations using interventionist action research methodology. To achieve this goal, I (the teacher and researcher) designed and implemented a digital feedback system and a digital assessment system in an undergraduate finance course at a business school. The feedback system, which can be tailor-made by business teachers, automatically provide individual feedback to students working on problem-solving tasks in a spreadsheet in order to support and improve their engagement and learning. On the foundations of the former innovation, another goal with the study was to develop and implement a digital assessment system supporting teachers when grading digital assignments and examinations in management accounting subjects. The methodology utilized includes many similarities with interventionist action research (IR), which has gained a foothold in qualitative management accounting research. IR focuses on realworld problem solving and the overall goal of contributing to theory building.
\end{abstract}

Keywords: teacher initiated curriculum innovations, formative feedback system, and summative assessment system 


\section{Introduction}

This paper reports on a longitudinal interventionist case study conducted by a teacher and researcher, i.e. the author of the paper. The overall purpose was to research my classroom practice in order to improve it, to inform the teaching profession, and to provide support to teachers in higher business education in their effort to integrate ICT into teaching and learning of management accounting subjects. In the approach outlined, I highlight the role of teachers in affecting classroom changes through their development and implementation efforts, thus changing education through individuals within the organization, i.e. bottom-up innovations. In this regard, interventionist action research may be an appropriate methodology to apply as showcased in this study. To this author's knowledge, this is the very first study published where interventionist's action research is applied within a management accounting education setting.

An intended contribution of this study was to develop a digital formative feedback system, which engage and support learners when solving financial problems in a spreadsheet. Formative feedback or professional feedback is a more or less a continuous process which is often described as feedback for learning (Shute, 2008). Formative feedback is in high demand in Norwegian higher education (Meld. St. 16 (2016-2017)). Software algorithms have the potential to provide detailed and helpful individual feedback to students effectively regarding their learning processes and outcomes (Marriott \& Lau, 2008; Evans, 2013). A related intended contribution of this study was to enable teachers in business economics to develop user-created digital content; that is, individualized problem-solving tasks for their own educational practices.

Consequently, on the foundations of the former innovation, another intended contribution of this study was to develop a digital summative assessment system supporting teachers when grading digital assignments and examinations in management accounting subjects. Summative feedback is assessment of learning (Knight, 2002; Marriott \& Lau, 2008). According to Knight (2002), summative assessment is 'the Achilles' heel of quality', and it has been shown that changes in curriculums and learning objectives are ineffective if assessment practices remain the same, since learning and teaching tend to be modelled against tests (ibid.). Moreover, computerprovided assessments can significantly ease the teacher's marking and grading workload (Gikandi et al., 2011).

I have organized the paper as follows. First, based on a literature review, I outline and link the interventionist research approach to management accounting research. Second, I describe the 
interventionist research process as practiced in the present study, and discuss the practical and theoretical outcomes thereof. Finally, I conclude the paper by reviewing contributions, implications and limitations.

\section{Management accounting research and interventionist action research}

Action research (AR) constitutes the origin of the interventionist action research approaches (IR) (Jönsson \& Lukka, 2007). Carkhuff (1985, p. 163) defines an intervention when stating the following: '... an intervention is both a response and an initiative. It is a response to a situation that defines a need. It is a response to a deficit or to what is not present. At the same time, it is an initiative to influence that situation-to fill in what is not present, to transform the deficits into assets. In short, an intervention is an attempt to make a difference.' The essence of IR is researching where practice and theory meet. IR has, according to Westin \& Roberts (2010), the potential to increase the relevance of management accounting research and is today accepted as a complementary and significant research tool.

Argyris et al. (1985) described intervention theory as a theory of action (theory-in-use), as did Kaplan (1993). IR draws from such areas as evaluation research, behavioral assessment, technology assessment, technological transfer, simulation and modelling, meta-analysis, knowledge utilization, practice technology and system engineering (Baard, 2010). It is the configuring of these methodological elements into a system of action that create practical intervening innovations (Thomas \& Rothman, 1994). Change is an inherent aspect of intervention research. Static situations with controllable subjects and objects are rarely a part of a dynamic practice (Westin \& Roberts, 2010). Researchers intervening in organizational systems have dual objectives: to advance knowledge in the field and to help improve the system under study (Baard, 2010). Interventionist research aspires to narrow the gap between practice and academic theory (Jönsson, 2010; Jönsson \& Lukka, 2007).

IR is a genre of applied research. It is based on a case or field study and has two outputs: a knowledge product for both researchers and practitioners and a practice product or intervention developed for problem solution (Thomas \& Rothmann, 1994). The aim of IR is to improve a reallife context effectively through the development of interventions. This involves a coordinated effort of all participants who are actually experiencing the problem. Apart from the generation of 
theoretical knowledge, the design and development of an intervention is the focal point of IR (Baard, 2010).

Thomas and Rothman (1994) indicated that there is no one particular research technique that is adopted in the design and development phase of an intervention. Both quantitative and qualitative research are used. Argyris (1974) encouraged researchers to apply traditional research methods for information gathering to promote the validity of the information on which intervention design is dependent.

An intensive search for both a practically and theoretically innovative solution is the primary feature distinguishing interventionist research from other types of action research (Kasanen et al., 1993.). According to Jönsson \& Lukka (2007), the purpose of an intervention is to balance the problem-solving oriented practical starting point of an IR study and the potential for theoretical contribution. Through intervention, the researcher develops in collaboration with the host organization a new construction, tests its usability and draws theoretical conclusions based on the process. Fundamentally, interventionist research comes close to the original ideas of Lewin (1946) on action research who stated 'One of the best ways to understand the world is to try to change it' (Argyris, et al., 1985, p. xii).

Table 1 extracts the phases of an interventionist research process.

\section{Table 1. Phases of an interventionist research process*}

Phase 1

Find a practically

relevant problem which

also has research

potential
A practical problem lies at the core of any interventionist research problem. Moreover, the development challenge should also be directly relevant to decision-makers in the host organization. The problem should also be theoretical significant, and there should not be any obvious solution available in literature. 
Phase 2

Obtain a general and

comprehensive

understanding of the

topic

Phase 3

Innovate, i.e. construct

a solution idea
To become familiar with both the practical and the theoretical underpinnings of the topic, the researcher need ex-ante knowledge of theory in order to make informed interventions and to identify and analyze theoretical contributions of the study.
An intensive search for both a practically and theoretically innovative solution is the primary feature distinguishing interventions research from other types of action research. The innovation phase is creative, and often heuristic. Cooperative teamwork between the researcher and host organization is crucial.

\section{Phase 4}

Implement the solution and test whether it works in practice

\section{Phase 5}

Examine the scope of the solution's applicability
In interventionist research, the implementation phase is an elementary part of the research process. It is critical to implement a construct, since even a failed trial may lead to theoretically interesting findings. A successful implementation means that the research process has been effective (at least partly) and that the construct is technically feasible.

In this phase, the researcher should consider the wider implications of the intervention, i.e. external validity. This involves discussing those aspects of the intervention that could be transferable to other organizations. In case of failed implementation, it is possible that problems are likely to emerge in other organizations. 


\section{Phase 6}

Show the theoretical connections and the research contribution of the solution concept.
There are two primary ways of contributing to theory from interventionist studies. First, the construct of itself is of such novelty that it introduces a new means to achieve certain ends. Second, an interventionist case study can serve the purpose of developing, refining or testing a theory.

* The table is compiled from Kasanen et. al. (1993), Labro \& Tuomela (2003), and Lukka (2003).

Most phases in the process overlap with the previous and following phases. Phases 3, 4 and 5 are particular related to ensure internal validity, while phase 6 deals with external validity (Labro \& Tuomela, 2003). The exact theoretical contribution can be elaborated upon only in the final part of the research process (ibid.).

Gaining and maintaining a commitment from the case company is crucial for the research process not to be abandoned at a too early a stage (Lukka, 2003). In an IR case study, the main issue is whether the case company has adopted the construct (ibid.). Nevertheless, IR case researchers should assess the transferability of their construct, at least to some extent (Labro \& Tuomela, 2003).

An important characteristic of an intervention is that the usability can be demonstrated through the implementation of the solution, as it is always difficult, if not impossible, to assess the practical adequacy of any new intervention prior to its implementation (Kasanen et al., 1993). Labro \& Tuomela (2003) provide transparency concerning validity issues by making a case for market-based validation of managerial constructs. The construct pass the weak market test when the host organization is willing to apply it to their actual decision-making problem. Lukka (2003) stated that the weak market test should refer to the actual implementation of the construct, rather than only being willing to implement it. The construct pass the semi-strong market test if it is widely adopted by organizations. Passing the strong market test requires that the organizations applying the construct systematically produce better results than those that are not using it (ibid.).

In addition to market based validation principles, Suomala \& Lyly-Yrjäinäinen (2012) also adopt a classification on the focal point of the intervention. This refers to the extent to which the researcher is directly intervening in management accounting practices and to what extent the focus of the intervention touches other disciplines such as education. 


\section{Interventionist action research as practiced in the present study}

In this section, I will discuss how I applied IR to improve my own classroom practice. To my knowledge, this is the first study ever published that apply interventionist's action research within a management accounting education setting. The structure of this section builds on the phases of the interventionist research process as described in Table 1. For the educational interventions reported, I will discuss the following features and link them to my classroom: 1) practical relevant problems with a research potential, 2) a comprehensive understanding of the topics, 3) innovative solutions, 4) solutions implemented and tested to work in practice, the 5) the scope of the solutions applicability, and finally 6) the theoretical connections and the research contribution of the solution concepts.

\section{Phase 1: Practical relevant problems with a research potential}

\section{The formative feedback problem}

One of the most obvious findings of educational research is that feedback has a significant effect on learning (e.g. Shute, 2008). However, in a large group of students that only meets once a week for lectures plus every other week for workshops, feedback and individual guidance can be sparse. Before starting the design and development process leading up to the digital formative feedback intervention, I found support in the literature, which confirmed that innovative uses of ICT could replace oral and paper-based feedback to some extent by providing learners with detailed reports, which describe strengths and weaknesses of their solutions, thus supporting formative assessments (Marriott \& Lau, 2008). Moreover, computer-provided feedback can significantly ease the teacher's marking and grading workload (Gikandi et al., 2011).

\section{The summative assessment problem}

When knowledge is assessed on a final written examination, the students often have to take a technological step back in which a pen, paper and a calculator still apply even when the use of

such traditional tools is becoming increasingly outdated. Reasonably, students have asked why it is so important to develop digital skills when they cannot actually use such expertise in their respective exams. One major reason why students are generally denied the opportunity to use computers is the lack of facilities (computers and premises) which can simultaneously handle 
hundreds of students taking their final examinations digitally. Johnson et al. (2011) reported that individual organizational constraints are likely to be the most important factors in decisions to adopt new technologies in education. Another reason is the fear that students may be tempted to cheat when using computers, which are connected to the Internet. However, due to the insistence of the students, the majority of the universities in Norway have been experimenting with digital examinations under various models.

\section{Phase 2: A comprehensive understanding of the topics}

\section{Understanding of the formative feedback problem}

Feedback is formative when the intention is to change students' thinking or behavior and help improve their learning outcomes (Shute, 2008). Feedback, motivation and learning are interrelated. In addition to enhancing learning outcomes, formative feedback can provide greater motivation for learning (ibid.). Learning motivation may also increase when a student experiences a certain level of mastery. In an academic context, the aim is often to master problem solving and in this regard, prompt and constructive feedback on students' performance can stimulate interest in this area (Wigfield \& Eccles, 2000). Professional feedback can also be provided digitally in the form of detailed personalized formative feedback on problem solving in a digital environment (e-feedback) (Denton et al., 2008).

\section{Understanding of the summative assessment problem}

The purpose of summative feedback is to measure the extent to which an intended learning outcome is achieved. An examination is an example of summative feedback (ibid.). Many learning objectives simply cannot be measured using standard paper and-pencil assessments such as building a financial simulation model on a spreadsheet from basic principles. Examination tasks are a powerful way to communicate what is really valued in students' learning (Nitko \& Brookhart, 2014). For example, teachers may inform their business students how important it is for them to develop spreadsheet skills to prepare for their future careers. However, if the assessments consist of questions, which only require a paper and pencil to solve them, then the students will know differently (ibid.). 


\section{Phase 3: Innovative solutions}

\section{The digital formative feedback innovation}

The remedy for the feedback problem experienced in my class was to develop interactive problem-solving tasks in Excel. Through this approach, I could automatically provide individual professional feedback to the students as necessary. Working on problem-solving tasks in a finance course is about applying economic theory to practical problems. According to Wagner (1995), solving practice problems stimulates the reasoning and development of various hypotheses regarding how a problem can be solved. This calls for an understanding of the underpinning theory.

The problem-solving tasks in the present study were designed to promote thinking and understanding by requiring the students to build financial models from basic principles. In addition, these tasks were practice-oriented so that the students could recognize and experience them as relevant. Biggs (1996) argued that tasks with an authentic touch might increase engagement and overall motivation as well as help students adopting to more advanced learning strategies and higher order cognitive thinking.

The design and development of the interactive problem-solving tasks has been a lengthy process. In the early stage of this development process, a creative idea came up on how to solve the consecutive error problem. In this regard, managing consecutive errors is fundamental for students to gain confidence in automatic feedback provided by a learning system. Automatic feedback is complicated by the risk of consecutive errors in calculations. A consecutive error is not an error caused by the student, but the result of an earlier error, which the student made in the calculation procedure, thus causing errors in subsequent calculations. To handle this situation, a feedback algorithm must detect and correct consecutive errors so that students are not successively penalized for the same error.

In the second cycle of development, the system was completely recoded so that a teacher without coding (programming) skills was capable to develop his/her own interactive problemsolving tasks in Excel. This was accomplished by developing a generic 'plug and play' VBA algorithm which was able to mark and provide automatic feedback to 'any' problem-solving task modelled in Excel. The scores and feedback provided were tailored to each student and they not only addressed the problem solving outcome, but also the problem-solving process. 
Using the generic marking and feedback algorithm, a teacher with proficient spreadsheet skills no longer had to use the 'out-of-the-box' problem-solving tasks that I had constructed for the undergraduate finance course. Instead, he/she could now create individualized problemsolving tasks for exercises, assignments and examinations within any subject, provided that the Excel spreadsheet software was a suitable tool for solving subject matter problems.

\section{The digital summative assessment innovation}

The problem regarding the limited capacity of data laboratories was resolved by allowing the students to bring their own PCs to the examination halls. There, the examinations were distributed and electronically collected by email. In addition, the more than one hundred examination papers were marked and graded automatically (as well as two compulsory assignments), which saved us who teaches the course a significant amount of time compared to the previous approach of manually marking and grading.

Since the students also have access to the Internet and their own hard disks during the examination, this can provide opportunities for communicating with others and cheating. However, in order to hinder cheating on examinations and assignments, several methods were employed. First, the students were given the same problem-solving tasks for the summative assessments, but with different numbers. Thus, no solutions were similar. Second, the data used in the formulas are located in different cells on the spreadsheets. Therefore, for a student, information from another student has little value. Finally, the workload on the examination was so heavy that the students had a strong incentive to focus on their own examinations.

\section{Phase 4: Solutions implemented and tested to work in practice}

This interventionist research project aimed to impact on practice by designing and developing interventions to solve complex problems in an authentic classroom setting. The formative feedback solution including interactive problem-solving tasks have been implemented and used by cohorts of more than one hundred students at this author's business school each year from 2008 to the present. In doing so, these tasks have become an established practice in the course. The innovative feedback system is able to provide instant and valid feedback as well as advice to learners and teachers concerning future learning strategies, based on the learners' individual needs (Bertheussen, 2014a). More recently, the feedback tool has been enriched to include tasks, 
which are more authentic and allow for business constructs, which have been difficult to assess such as regression analysis and optimization problems (ibid.).

As the digital assessment artefact is the flipped side of the formative feedback system, it has to date been through approximately 20 iterations, including compulsory assignments and final examinations. Consequently, digital tests in the undergraduate finance course performed on students' own PCs have become an established assessment practice at my business school. Table 2 outlines the practical artefacts resulting from this study.

\section{TABLE 2. PRACTICAL OUTPUT FROM THE STUDY*}

Artefact 1 A formative feedback system that supports a teacher who wants to tailor-
make problems-solving tasks, which are implemented in a spreadsheet and
provide automatic formative feedback to a student.

Artefact 2 A summative assessment system that supports a teacher in developing a tailor-made digital examination practice.

Artefact $3 \quad$ Implementation guide - supplement to Artefact $1 \& 2$.

* These are open source systems and documents available from the author.

\section{Phase 5: The scope of the solutions applicability}

The digital tools that have been developed and implemented in this case study are context-bound to educational management accounting subjects. The formative feedback system as well as the summative assessment systems reported were both underpinned by interactive problem-solving tasks, which can be tailor-made by a teacher based on their individual needs (Bertheussen, 2014a). However, the interactive concept requires that the problem-solving tasks should have an undemanding structure and limited scope. Nevertheless, this is a distinctive characteristic with problem-solving tasks in basic and intermediate business economic subjects such as financial accounting and managerial accounting (ibid.). I therefore believe that the concept may have appeal beyond the undergraduate finance course. In addition, by implementing the practices into other business economic subjects and at a more advanced level will allow for more replications and improve the generalizability of the interventions. The systems are open source tools that 
allow teachers to create customized digital learning and assessment interventions by adapting them to fit their individual teaching styles as well as their learners' needs. By taking these systems as a point of departure, practitioners can experience a more rapid implementation of the presented systems with less effort.

\section{Phase 6: The research contribution of the solution concept}

An important contribution from an interventionist action research study is theory building, which advances our knowledge regarding the characteristics of the interventions and the process of designing and developing them. As an interventionist researcher I had to straddle between the emic (insider) world that was followed during the empirical phase in particular, and the etic (outsider) world that was required in reflection and for deriving broader theoretical implications based on the empirical evidence (Suomala \& Lyly-Yrjänäinen, 2012). Consequently, five refereed scientific articles have been produced that are directly related to Artefact $1 \& 2$ during this research and development project.

\section{TABLE 3. THEORETICAL OUTPUT FROM THE STUDY}

\section{Paper Research problem}

Bertheussen

A theoretical justification of Artefact $1 \& 2$ by examining whether it is less academically demanding to solve subject matter problems using an ICT tool than on paper.

Bertheussen $\quad$ Outlines the design principles underpinning Artefact $1 \& 2$. (2014a)

Bertheussen An evaluation study of Artefact 1 based on survey data. (2014b)

Bertheussen \& An evaluation study of Artefact 1 based on longitudinal data that was Mydland (2016) automatically collected when students used the artefact.

Bertheussen An evaluation study of Artefact 2 based on content analysis of (2016) examination papers, which were marked and graded automatically. 


\section{Discussion and conclusion}

The intended purpose of this study was to improve management accounting education through teacher initiated curriculum innovations using interventionist action research methodology. When I returned to a university college after having worked in business for more than twenty years, it seemed like the rapid technological development in society had passed academia unnoticed as information and communication technology was underutilized in the learning and assessment activities. Accordingly, I got a sense of educational relevance that was lost. Against this backdrop, I decided to design, develop and implement digital learning and assessment interventions within a finance course in higher education, which could contribute to student engagement and learning, and as well off load teachers when grading digital assignments and examinations in management accounting subjects. In retrospect, I found that the overarching methodology applied has clear similarities with IR, which is a practical research methodology that can help bridge the gap between research and practice in the field of management accounting (e.g. Baard, 2010; Jönsson \& Lukka, 2007; Kasanen et al., 1993; Labro \& Tuomela, 2003; Suomala et al., 2014).

\section{The digital formative feedback innovation}

In a large group of students which only meets once a week for lectures (plus every other week for workshops), feedback and individual guidance will be insufficient. To solve this problem of feedback shortage, I decided to design, develop and implement interactive problem-solving tasks

within the curriculum. The spreadsheet-based tasks provided individual formative feedback to the learners on both the problem-solving outcomes as well as on the problem-solving processes (Bertheussen, 2014b). By means of VBA, the programming language embedded within the Excel spreadsheet software, I was able to build 'artificial intelligence' into the spreadsheet-based problem-solving tasks and make them interactive. In this regard, an interactive problem-solving task is basically an inactive traditional spreadsheet-based task with a marking and feedback algorithm attached (Bertheussen, 2014a). The interactive tasks, which are digital learning resources in micro format, are considered an educational innovation in this study. In a later cycle of the intervention process, the system was further developed so that a teacher with no programming skills can tailor-make problem-solving tasks to his/her subject context and develop an individual digital formative feedback practice (ibid.) 


\section{The digital summative assessment innovation}

Students have questioned why it is so important to develop digital skills when they cannot actually use such expertise in their respective examinations. This was seen, inter alia, in the $W e$ Want PCs on our Exam student campaign in Norway, which occurred during autumn 2011. One reason why institutions deny students the use of computers is the lack of facilities (e.g. computers and premises) which can simultaneously handle hundreds of students undertaking their final examinations digitally. To establish a large-scale digital examination practice, required deliberate cooperation among relevant stakeholders such as the faculty (which permitted the practice), the teachers (who developed the semi-individual exam tasks and validated the examination practice) and the students (who brought their own laptops).

\section{Contributions}

According to Lukka (2003), if we consider a study where the intervention has taken the form of a new construction, two types of theoretical contributions are highlighted. First, the new construction in itself may be a contribution to the design knowledge in the area (e.g. Bertheussen, 2014a). This requires that the researcher is able to show how the new construction has contributed to a desirable result in a given situation (Bertheussen, 2014a; 2016). Such a contribution may assume the status of a design concept that is of interest to practitioners because it works and to fellow researchers because it may constitute a starting point for further testing.

Both constructions resulting from this study have been implemented and tested (Bertheussen, 2014a; 2016). Moreover, the learning outcome from students by engaging in the digital learning and assessment interventions in the blended course design has been empirically tested through surveys (Bertheussen, 2014b) and time series data analysis (Bertheussen \& Mydland, 2016). In addition, the relationships that have been made visible in explaining why the constructions worked (Bertheussen, 2014a; 2014b; 2016) or were used in designing the construction, may provide building blocks for further constructions. The main characteristics of these constructs are likely to be readily adaptable to accounting management teachers so that the knowledge is not lost to the profession. In the present study, the constructs are all open source documents.

As the practice of educational management accounting is embedded within the operations and activities of a real-life business school, this IR project was primarily aimed at contributing to 
learning and teaching. However, the present study also demonstrated that interventions might relate to educational change processes in several ways. The target of an intervention can sometimes be directly related to a learning process (Bertheussen, 2014a), a teaching process or an administrative process that aim to support learning and/or teaching processes (Bertheussen, 2016). The processes are, however, intertwined and consequently an intervention intending to improve a learning process may have some reflections on teaching and administrative processes.

Finally, knowledge sharing with the business teacher profession has been a significant aim of this study. In addition to the resulting artefacts and papers, knowledge from the present study has been shared with a colleague, and as a by-product, two papers have been published on educational interventions in introductory management accounting subjects in higher business education (Heimly \& Bertheussen, 2016a; 2016b).

\section{Implications}

A wider policy implication of this study, which is in line with Hennessy et al. (2005), entails a shift from a technologically driven model of ICT integration towards one based on teacher involvement. This implies encouraging teachers to network and exchange good practices on ICT use in their subject teaching and learning. The involvement of teachers in discussions about viable ICT-enhanced learning and assessment interventions may also encourage them to develop and implement other innovative educational practices supported by ICT, as exemplified by this study. To establish and support good practices, it is necessary to support teachers engaging in educational development interventions involving ICT and encourage them to exchange their experiences (Redecker \& Johannessen, 2013). The approach outlined in this study highlights the role of practitioners in affecting classroom changes through their development and implementation efforts, thus changing education through teacher (or bottom-up) innovations.

\section{Limitations}

This study was conducted in an authentic classroom setting with the purpose of developing theoretical insights and practical solutions in a particular context. As such, the study retains a high degree of ecological validity (Brewer, 2000). In an ecologically valid study, the methods, materials and settings are close to the real-life situation under investigation (Gutiérrez \& Penuel, 2014). Nevertheless, the focus was on interventions within a specific context and I attempted to 
study these as integral and meaningful phenomena. The context-bound nature of the research explains why it does not strive towards context-free generalizations. Therefore, the findings cannot be generalized to a larger universe because there is no statistical generalization from sample to population in a case study, as in the case of survey research (Yin, 2014).

In interventionist action research, there are generalization concerns both regarding the transfer of theoretical insights and regarding the transfer of practical interventions into other settings. Consequently, an effective intervention should be able to migrate from an experimental classroom to average classrooms operated by average teachers (Brown, 1992). However, there are so many factors at play when interventions 'go live' that replication differs from replication in the laboratory sense (Reinking \& Bradley, 2008). Consequently, in the present study, I attempted to explicate the 'local conditions' as an integrated element of the research and development process.

Participant research involves active engagement of the researcher in the case being studied to the extent that it influences the activities and discourse that occur (Guba \& Lincoln, 1994). The core criticism of the participant researcher is that the proximity of the investigator to the situation being researched can cause biased collection, interpretation and/or reporting. In the present study, I approached this issue by drawing my perspectives, motives and background for conducting the research into the analysis and by integrating it into existing theory as outlined in the previous section of this paper. From this perspective, the fact that the research was based upon real teaching in the field and was conducted by a teacher who has improved his practice through a methodological approach to research and development is a potentially valuable aspect of the study (Gutiérrez \& Penuel, 2014).

\section{Future research efforts}

Baard et al. (2010) suggested that interventionist research that results in a validated and effective intervention, as a solution to the problem under study, can be followed by effect studies. Effect studies may range from small-scale learning experiments to large-scale comparative tests, e.g. via randomized controlled trials. Although several effect studies have been conducted as an integral part of the current research project (Bertheussen, 2014b; 2016; Bertheussen \& Mydland, 2016), I did not utilize a control group. In addition, I did not attempt to differentiate the learning effect of applying spreadsheets to enhance subject learning from other pedagogical approaches in the course design. Therefore, the interventions do not pass the strong market test, as it requires that 
an organization applying the construct systematically produce better results than those that are not using it (Lukka, 2003).

Accordingly, there is a need for more research, i.e. to measure the success of the innovative formative feedback intervention presented in this study compared to a more traditional feedback practice. This can be completed by randomly assigning students to either a treatment group or a control group and comparing the measures of feedback effectiveness. Future studies should address these methodological issues, even though there are obvious practical and ethical concerns of exposing students to different formative feedback systems as they attend the same course at the same university. 


\section{REFERENCES}

Argyris, C., \& Schön, D. C. (1974). Theory in Practice: Increasing Professional Effectiveness. Jossey-Bass, San Francisco, CA.

Argyris, C., Putnam, R., \& Smith, D. M. (1985). Action science. San Francisco: Jossey-Bass.

Bertheussen, B. A. (2012). Ruteark eller regneark. Kognitive utfordringer med å løse finansoppgaver på papir og PC. Uniped, 35(3), 87-101.

Bertheussen, B. A. (2014a). Power to business professors. Automatic grading of problem-solving tasks in a spreadsheet. Journal of Accounting Education, 32 (1), 76-87.

Bertheussen, B. A. (2014b). Automatisk formativ feedback kan gi god motivasjon og læring. Uniped, 37(4), 59-71.

Bertheussen, B. A. (2016). Validating a Digital Assessment Practice. Journal of Financial Education, 42(1), 187-204.

Bertheussen, B. A., Myrland, Ø. (2016). Relation between academic performance and students' engagement in digital learning activities. Journal of Education for Business, 91(3), 1-7.

Baard, V. (2010). A critical review of interventionist research. Qualitative Research in Accounting \& Management, 7(1), 13-45.

Biggs, J. (1996). Enhancing teaching through constructive alignment. Higher Education, 32(3), $347-364$.

Brewer, M. B. (2000). Research design and issues of validity. Handbook of research methods in social and personality psychology, 3-16.

Brown, A. L. (1992). Design experiments: Theoretical and methodological challenges in creating complex interventions in classroom settings. The journal of the learning sciences, 2(2), 141178.

Casner-Lotto, J., \& Barrington, L. (2006). Are They Really Ready to Work? Employers' Perspectives on the Basic Knowledge and Applied Skills of New Entrants to the 21st Century US Workforce. Washington DC: Partnership for 21st Century Skills.

Carkhuff, R. R. (1985). Productive problem solving. Human Resource Development Press. Amherst: Massachusetts.

Denton, C. A., Wexler, J., Vaughn, S., \& Bryan, D. (2008). Intervention provided to linguistically diverse middle school students with severe reading difficulties. Learning Disabilities Research \& Practice, 23(2), 79-89. 
Eisenhardt, K.M., Graebner, M.E. (2007). Theory building from cases: opportunities and challenges. Academy of Management Journal, 50(1), 25-32.

Evans, C. (2013). Making sense of assessment feedback in Higher Education. Review of Educational Research, 83(1), 70-120.

Geertz, C. (1973). Thick description: Toward an interpretive theory of culture. In C. Geertz (Ed.), The interpretation of cultures. New York: Basic Books.

Gikandi, J. W., Morrow, D., \& Davis, N. E. (2011). Online formative assessment in higher education: A review of the literature. Computers \& Education, 57(4), 2333-2351.

Guba, E. G., \& Lincoln, Y. S. (1994). Competing paradigms in qualitative research. Handbook of qualitative research, (2), 163-194.

Gutiérrez, K. D., \& Penuel, W. R. (2014). Relevance to practice as a criterion for rigor. Educational Researcher, 43(1), 19-23.

Heimly, F-S., \& Bertheussen, B. A. (2016a). Speilvendte klasserom kan bidra til bedre akademiske prestasjoner i høyere akademisk utdanning. Uniped, 39(1), 47-60.

Heimly, F-S., \& Bertheussen, B. A. (2016b). Et fors $\varnothing \mathrm{k}$ på å integrere praksis i høyere $\emptyset$ konomisk utdanning. Beta - The Scandinavian Journal of Business Research, 30(1), 29-41.

Hennessy, S., Ruthven, K., \& Brindley, S. (2005). Teacher perspectives on integrating ICT into subject teaching: commitment, constraints, caution, and change. Journal of curriculum studies, 37(2), 155-192.

Johnson, H. T. and R. S. Kaplan (1987). Relevance Lost. Harvard Business School Press. Boston: MA.

Jönsson, S. (2010). Intervention - an approach for the future? Qualitative Research in Accounting and Management 7, 124-134.

Jönsson, S., \& Lukka, K. (2007). There and back again: doing interventionist research in management accounting. In: Chapman, C.S., Hopwood, A.G., Shields, M.D. (Eds.), Handbook of Management Accounting Research, 1, 373-397.

Kahu, E. R. (2013). Framing student engagement in higher education. Studies in higher education, 38(5), 758-773.

Kasanen, E., Lukka, K. \& Siitonen, A. (1993). The constructive approach in management accounting research. Journal of Management Accounting Research, 5, 243-264. 
Kaplan, R.S. (1993). Research opportunities in management accounting. Journal of Management Accounting Research 5, 1-14.

Knight, P. T. (2002). Summative assessment in higher education: practices in disarray. Studies in higher education, 27(3), 275-286.

Labro, E. \& Tuomela, T-S. (2003). On bringing more action into management accounting research: process considerations based on two constructive case studies. European Accounting Review, 12 (3), 409-442.

Lewin, K. (1946). Action research and minority problems. Journal of social issues, 2(4), 34-46.

Lowther, D. L., Inan, F. A., Daniel Strahl, J., \& Ross, S. M. (2008). Does technology integration “work” when key barriers are removed? Educational Media International, 45(3), 195-213.

Lukka, K. (2003). The constructive research approach. Case study research in logistics. Publications of the Turku School of Economics and Business Administration, Series $B, 1(2003), 83-101$.

Lukka, K., \& Kasanen, E. (1995). The problem of generalizability: anecdotes and evidence in accounting research. Accounting, Auditing \& Accountability Journal, 8(5), 71-90.

Marriott, P., \& Lau, A. (2008). The use of on-line summative assessment in an undergraduate financial accounting course. Journal of Accounting Education, 26 (2), 73-90.

Meld. St. 16 (2016-2017). Kultur for kvalitet i høyere utdanning. https://www.regjeringen.no/no/dokumenter/meld.-st.-16-20162017/id2536007/

Nitko, A. J., \& Brookhart, S. M. (2014). Educational assessment of students. Sixth edition. Prentice-Hall.

Ramsden, P. (1992). Learning to Teach in Higher Education. London: Routledge.

Redecker, C., \& Johannessen, Ø. (2013). Changing Assessment-Towards a New Assessment Paradigm Using ICT. European Journal of Education, 48(1), 79-96.

Reinking, D., \& Bradley, B. A. (2008). On formative and design experiments: Approaches to language and literacy research. New York: Teachers College Press.

Ross, S. M., Morrison, G. R., \& Lowther, D. L. (2010). Educational technology research past and present: Balancing rigor and relevance to impact school learning. Contemporary Educational Technology, 1(1), 17-35.

Scouller K. (1998). The effect of assessment method on students' learning approaches: Multiple choice question examination versus assignment essay. Higher Education 35, 453-472. 
Shute, V. J. (2008). Focus on formative feedback. Review of Educational Research, 78 (1), 153189.

Suomala, P., Lyly-Yrjänäinen, J., (2012). Management Accounting Research in Practice. Lessons Learned from an Interventionist Approach. New York: Routledge.

Suomala, P., Lyly-Yrjänäinen, J., \& Lukka, K. (2014). Battlefield around interventions: A reflective analysis of conducting interventionist research in management accounting. Management Accounting Research, 25(4), 304-314.

Thomas, E. J., \& Rothman, J. (1994). An integrative perspective on intervention research. In J. Rothman \& E. J. Thomas (Eds.), Intervention research: Design and development for the human services (3-20). New York: Haworth.

Wagner, E. D., \& McCombs, B. L. (1995). Learner Centered Psychological Principles in Practice: Designs for Distance Education. Educational technolog, 35(2), 32-35.

Westin, O., \& Roberts, H. (2010). Interventionist research-the puberty years: an introduction to the special issue. Qualitative Research in Accounting \& Management, 7(1), 5-12.

Wigfield, A., \& Eccles, J. S. (2000). Expectancy-value theory of achievement motivation. Contemporary educational psychology, 25(1), 68-81.

Yin, R. K. (2014). Case study research: Design and methods. Sage publications. 